(2) Open Access Full Text Article

\title{
Design, synthesis, and structure-activity relationships of 2-benzylidene-I-indanone derivatives as anti-inflammatory agents for treatment of acute lung injury
}

This article was published in the following Dove Press journal:

Drug Design, Development and Therapy

\author{
Siyang Xiao',* \\ Wenxin Zhangl,* \\ Hongjin Chen' \\ Bo Fang' \\ Yinda Qiu \\ Xianxin Chen' \\ Lingfeng Chen' \\ Sheng Shu' \\ Yali Zhang' \\ Yunjie Zhao' \\ Zhiguo Liu' \\ Guang Liang' \\ 'Chemical Biology Research Center, \\ School of Pharmaceutical Sciences, \\ Wenzhou Medical University, \\ Wenzhou, Zhejiang, China; ${ }^{2}$ College \\ of Life and Environmental Science, \\ Wenzhou University, Wenzhou, \\ Zhejiang, China \\ *These authors contributed equally \\ to this work
}

\begin{abstract}
Purpose: The purpose of this study was to design and synthesize novel 2-benzylidene-1indanone derivatives for treatment of acute lung injury.

Methods: A series of 39 novel 2-benzylidene-indanone structural derivatives were synthesized and evaluated for anti-inflammatory activity in lipopolysaccharide (LPS)-stimulated murine primary macrophages.

Results: Most of the obtained compounds effectively inhibited the LPS-induced expression of IL- 6 and TNF- $\alpha$. The most active compound, $8 \mathbf{8}$, was found to significantly reduce LPSinduced pulmonary inflammation, as reflected by reductions in the concentration of total protein, inflammatory cell count, as well as the lung wet/dry ratio in bronchoalveolar lavage (BAL) fluid. Furthermore, $\mathbf{8} \mathbf{f}$ effectively inhibited mRNA expression of several inflammatory cytokines after LPS challenge in vitro and in vivo. Administration of $\mathbf{8} \mathbf{f}$ also blocked LPS-induced activation of the proinflammatory NF-KB/MAPK signaling pathway.

Conclusion: The simple synthetic preparation and biological properties of these derivatives make these 2-benzylidene-indanone scaffolds promising new entities for the development of anti-inflammatory therapeutics for the treatment of acute lung injury.
\end{abstract}

Keywords: indanone, acute lung injury, drug design, anti-inflammation, synthesis

\section{Introduction}

Acute lung injury (ALI) is characterized by neutrophil infiltration into the lung interstitium and airways, and the development of several disorders including pneumonia, aspiration syndromes, sepsis, and major trauma and shock. ${ }^{1,2}$ Despite extensive research, the mortality rate from ALI remains high, at $\sim 40 \%$, which is similar to that of breast cancer. Effective methods of treating acute inflammatory disease are extremely limited at present. ${ }^{3}$ Increasing evidence indicates that dysregulation of cytokines is an important step in mediating, amplifying, and perpetuating ALI processes. These cytokines mainly include tumor necrosis factor- $\alpha$ (TNF- $\alpha$ ), interleukin-6 (IL-6), IL-1 $\beta$, IL-12, and IL-8. ${ }^{4,5}$ Observations strongly suggest that the inflammatory processes occur in association with lung injury, and effective treatment should be given early in the ALI development process. Therefore, the development of anti-inflammatory candidates to inhibit the excessive production of cytokines, including IL- 6 and TNF- $\alpha$, has been a promising strategy for the prevention and treatment of ALI. This research has also provided a new direction for anti-inflammatory drug development. ${ }^{6,7}$ 
Xanthohumol (XAN) is a major chalcone derivative isolated from hops (Humulus lupulus L.), which contains the bitter flavors commonly used in brewing and medicine. ${ }^{8}$ XAN displays a wide range of biological activities, including anticancer, ${ }^{9,10}$ anti-oxidation, ${ }^{11}$ and properties that prevent and treat diabetes. ${ }^{12,13}$ Moreover, XAN has been reported to have additional anti-inflammatory effects via the downregulation of NF- $\mathrm{KB}$ activation in lipopolysaccharide (LPS)-stimulated RAW264.7 macrophages. ${ }^{14}$ Unfortunately, XAN has an acute problem due to poor solubility in an aqueous solution and poor bioavailability $(<1 \%)$, which poses a severe limitation for pharmacological application. ${ }^{15}$ 1-indanone, with a benzocyclopentanone skeleton, is a naturally occurring component found in various edible natural plants and is a useful synthons for synthesis of various carbocyclic and heterocyclic molecules. Thus, it may be used in the preparation of key intermediates for several drugs and natural products. ${ }^{16,17}$ Studies have been performed showing that compounds possessing a 1-indanone moiety are of great pharmacological importance, as they exhibit various beneficial biological activities, including anti-inflammatory, anticancer, antioxidant, and antimicrobial properties. ${ }^{18,19}$ In addition, several important drugs contain 1-indanone as a core moiety, such as Donepezil, which in 1996 was approved by the US Food and Drug Administration (FDA) for the treatment of moderate-to-severe Alzheimer's disease. ${ }^{20}$

Considering the structural similarity that exists between chalcone and 1-indanone, and since the hydroxyl group contributes to improving the pharmacological profile of bioactive compounds, we designed and synthesized 20 novel 2-benzylidene-1-indanone derivatives by substituting a hydroxyl group at the C-6 position of indanone (Figure 1). In vitro profiling indicated that $\mathbf{4 d}$ showed the promising anti-inflammatory activity against LPS-induced TNF- $\alpha$ expression ( $\%$ inhibition $=83.73 \%)$, but lacked potency in
IL-6 (\% inhibition=69.28\%) in RAW 264.7 macrophages. To improve the inhibition of IL-6, we further performed a lead optimization program to modify the A ring of the $4 \mathbf{d}$ to yield 19 new 2-benzylidene-1-indanone derivatives. Preliminary structure-activity relationship (SAR) analyses were performed to outline the relationships between structures and their pharmacological activity. The active compound 8 f showed improved anti-inflammatory activities in vitro and significant therapeutic effects in a mouse model, suggesting the potential of 2-benzylidene-1-indanone derivatives for the development of new anti-inflammatory agent for the treatment of ALI.

\section{Materials and methods Chemical experimental procedures}

The syntheses of the 2-benzylidene-1-indanone derivatives (4a-t and 8a-s) are summarized in Schemes 1 and 2. As depicted in Scheme 1, tetrahydropyranyl (THP) protection of commercially available 6-hydroxy-1-indanone (1) obtained 6-[(tetrahydro-2H-pyran-2-yl)oxy]-1-indanone (2), which was subjected to a key Claisen Schmidt condensation with various benzaldehydes to give THP protected 2-benzylidene1-indanone intermediates (3a-b, 3e-t) in the presence of ethanolic sodium hydroxide. Deprotection of the above intermediates with hydrochloric acid in ethanol gave the desired 2-benzylidene-1-indanone derivatives $\mathbf{4 a - b}$ and $\mathbf{4 e - t}$. Alternatively, Aldol condensation between 6-hydroxy-1-indanone (1) and hydroxyl-benzaldehydes using hydrochloric acid gas as a catalyst gave the products $\mathbf{4 c}$ and $\mathbf{4 d}$. Similarly, as described in Scheme 1, a condensation reaction catalyzed by acid or base was utilized to synthesize the desired 2-benzylidene-1indanone derivatives 8a-s with 4-hydroxy-3-methoxybenzaldehyde and substituted 1-indanones as the start materials (Scheme 2). All of the target compounds were characterized by ${ }^{1} \mathrm{H}-\mathrm{NMR},{ }^{13} \mathrm{C}-\mathrm{NMR}$, and ESI-MS. The analytical and spectral data of the final compounds are in full agreement

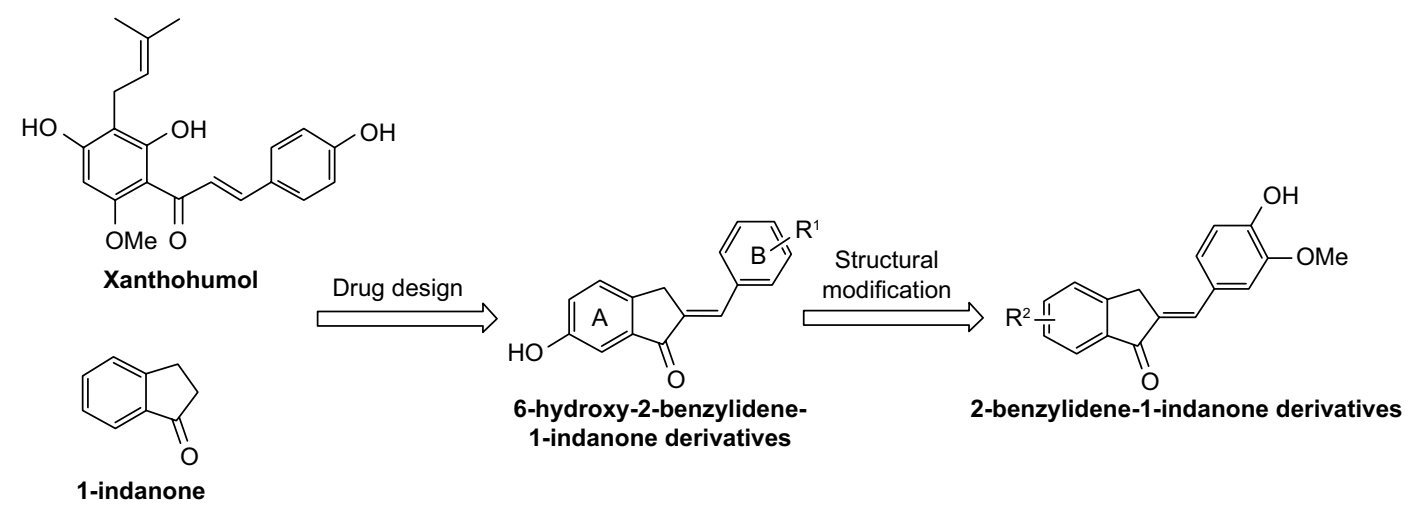

Figure I Design strategy based on I-indanone and anti-inflammatory natural product XAN. Abbreviation: XAN, xanthohumol. 


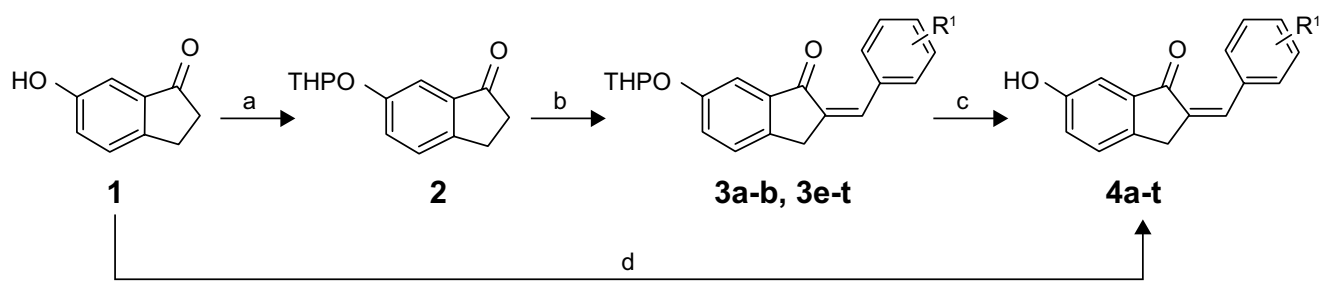

Synthesis of compounds $\mathbf{4 c}$ and $\mathbf{4 d}$

Scheme I General synthetic method for 6-hydroxyl-2-benzylidene-I-indanone derivatives 4a-t. Reagents and conditions: (a) 3,4-dihydro- $2 \mathrm{H}_{\text {-pyran, }} \mathrm{PPTS}, 4 \mathrm{~h}, \mathrm{CH}_{2} \mathrm{Cl}_{2}, 40{ }^{\circ} \mathrm{C}$; (b) various benzaldehydes, $\mathrm{EtOH}, 20 \%$ (w/v) $\mathrm{NaOH}$, room temperature, overnight; (c) $1.0 \mathrm{~mol} / \mathrm{L} \mathrm{HCl}$, EtOH, room temperature, 5 h; (d) $\mathrm{HCl}$ (gas), EtOH, room temperature, overnight.

with the proposed structures. The detailed synthesis and spectral characterization of new or unreported compounds are described in the Supplementary materials.

\section{Animals}

The animal protocol was approved by Wenzhou Medical University Animal Policy and Welfare Committee (Approval documents: 2013/APWC/0361). Male C57BL/6 mice weighing 18-22 g were purchased from the Animal Center of Wenzhou Medical University (Wenzhou, China). Animals involved in this experiment were treated in accordance with the Guide for Care and Use of Laboratory Animals of National Institutes of Health. Animals were maintained in sterile microisolator cages and fed autoclaved-pelleted diet and water ad libitum.

\section{Cells and reagents}

LPS were purchased from Sigma (St Louis, MO, USA). Saline was prepared as $0.9 \% \mathrm{NaCl}$ solution. The mouse IL-6 enzyme-linked immunosorbent assay (ELISA) kit and mouse TNF- $\alpha$ ELISA kit were purchased from eBioscience, Inc.
(San Diego, CA, USA). C57BL/6 mice were intraperitoneally injected with $6 \%$ thioglycollate solution $(0.3 \mathrm{~g}$ beef extract, $1 \mathrm{~g}$ tryptone, $0.5 \mathrm{~g} \mathrm{NaCl}$ dissolved in $100 \mathrm{~mL} \mathrm{ddH}_{2} \mathrm{O}$, and filtrated through $0.22 \mu \mathrm{m}$ filter membrane, $3 \mathrm{~mL}$ per mouse) and kept in pathogen-free conditions for 3 days before the isolation of murine peritoneal macrophages (MPMs). Total MPMs were harvested by washing the peritoneal cavity with RPMI-1640 medium (Gibco/BRL life Technologies, Eggenstein, Germany), centrifuged, and suspended in RPMI1640 medium (Gibco/BRL life Technologies), with 10\% fetal bovine serum (Hyclone, Logan, UT, USA), 100 U/mL penicillin, and $100 \mathrm{mg} / \mathrm{mL}$ streptomycin. Nonadherent cells were removed by washing with medium $4 \mathrm{~h}$ after seeding. Before treatment, MPMs were cultured in $35 \mathrm{~mm}$ plates and incubated overnight at $37^{\circ} \mathrm{C}$ in $5 \% \mathrm{CO}_{2}$-humidified air.

\section{Anti-inflammatory evaluation of synthetic compounds}

The inhibition effects of IL- 6 and TNF- $\alpha$ release of novel 2-benzylidene-1-indanone derivatives were evaluated in LPS-stimulated MPMs, as previously described. ${ }^{21}$ After

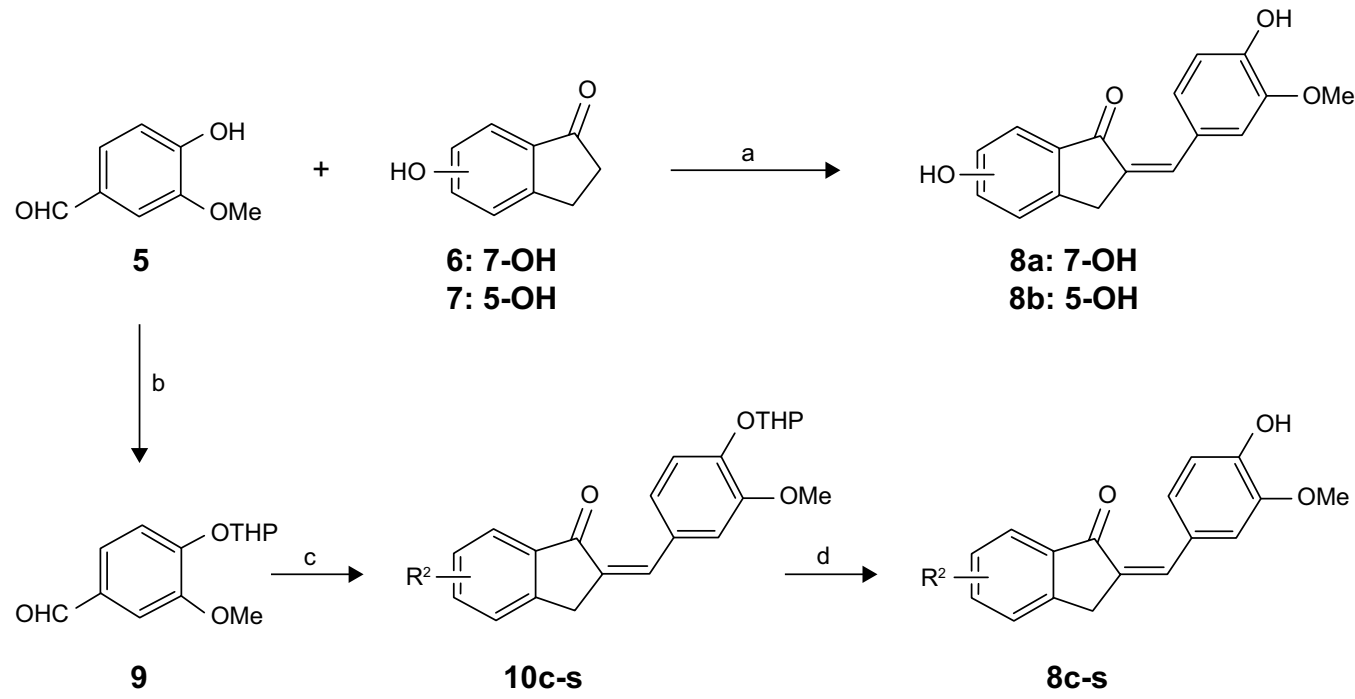

Scheme 2 General synthetic method for 2-benzylidene- I-indanone derivatives 8a-s; Reagents and conditions: (a) $\mathrm{HCl}$ (gas), EtOH, room temperature , overnight; (b) 3,4-dihydro$2 \mathrm{H}$-pyran, PPTS, $4 \mathrm{~h}, \mathrm{CH}_{2} \mathrm{Cl}_{2}, 40^{\circ} \mathrm{C}$; (c) various benzaldehydes, $\mathrm{EtOH}, 20 \%$ (w/v) NaOH, room temperature, overnight; (d) I.0 mol/L HCl, EtOH, room temperature, $5 \mathrm{~h}$. 
treatment of cells with indicated compounds and LPS, the TNF- $\alpha$ and IL-6 levels in medium were determined by an ELISA kit (eBioScience, San Diego, CA, USA) according to the manufacturer's instructions. Briefly, cells were seeded into six-well plates at a density of $5 \times 10^{5}$ cells per well in Dulbecco's Modified Eagle's Medium and incubated at $37^{\circ} \mathrm{C}$ in $5 \% \mathrm{CO}_{2}$ for $24 \mathrm{~h}$. Cells were pretreated with $10 \mu \mathrm{M}$ compounds for $30 \mathrm{~min}$, then treated with LPS $(0.5 \mu \mathrm{g} / \mathrm{mL})$ for $24 \mathrm{~h}$. After treatment, the culture media and cells were collected separately. The levels of TNF- $\alpha$ and IL- 6 in the media were determined by ELISA. The total protein in cultural plates was collected, and the concentrations were determined using Bio-Rad protein assay reagents (Bio-Rad Laboratories; Hercules, CA, USA). The total amount of the inflammatory factor in the media was normalized to the total protein amount of the viable cell pellets.

\section{Assessment of cytotoxicity of synthetic compounds}

To assess the safety of the 2-benzylidene-1-indanone derivatives, compounds were tested for their toxicity in the MPMs by MTT at a concentration of $10 \mu \mathrm{M}$. MPMs were cultured in 96-well plates at a density of 5,000 cells per well in 1640 medium, supplemented with $10 \%$ heat inactivated serum, $100 \mathrm{U} / \mathrm{mL}$ penicillin, and $100 \mathrm{mg} / \mathrm{mL}$ streptomycin. The cells were incubated at $37^{\circ} \mathrm{C}$ in $5 \% \mathrm{CO}_{2}$-humidified air. Compounds were dissolved in dimethyl sulfoxide (DMSO) and diluted with 1640 medium to the final concentrations of $10 \mu \mathrm{M}$ and incubated for $24 \mathrm{~h}$ before the MTT assay. ${ }^{22}$ The solution of MTT $(5 \mathrm{mg} / \mathrm{mL})$ dissolved in $\mathrm{NaCl}$ solution $(0.9 \%)$ was added to each well of the $96-$-well plate and incubated for $4 \mathrm{~h}$. After treatment with DMSO (150 $\mu \mathrm{L} /$ well $)$, the plate was analyzed in a multi-well-plate reader at $490 \mathrm{~nm}$.

\section{Real-time quantitative PCR}

Cells were homogenized in TRIZOL kit (Invitrogen, Carlsbad, CA) for extraction of RNA according to each manufacturer's protocol. Both reverse transcription and quantitative PCR were carried out using a two-step M-MLV Platinum SYBR Green qPCR SuperMix-UDG kit (Invitrogen). Eppendorf Mastercycler ep realplex detection system (Eppendorf, Hamburg, Germany) was used for quantitative PCR analysis. The primers of genes including TNF- $\alpha$, IL-6, IL- $1 \beta$, VCAM-1, ICAM-1, and $\beta$-actin were synthesized by Invitrogen. PCR primers were designed using Primer Premier Version 5.0 software (Premier Biosoft, Palo Alto, CA, USA), and sequences were as follows (Invitrogen):

TNF- $\alpha$ sense: 5'-TGGAACTGGCAGAAGAGG-3'; antisense: 5'-AGACAGAAGAGCGTGGTG-3'.
IL-6 sense: 5'-GAGGATACCACTCCCAACA GACC-3';

antisense: 5'-AAGTGCATCATCGTTGTTCAT ACA-3'.

IL-1 $\beta$ sense: $5^{\prime}$-ACTCCTTAGTCCTCGGCCA-3' antisense: 5'-CCATCAGAGGCAAGGAGGAA-3'

$\beta$-actin sense: 5'-TGGAATCCTGTGGCATCCATG

AAAC-3';

antisense: 5'-TAAAACGCAGCTCAGTAACAG TCCG-3'.

VCAM-1 sense primer: 5'-TGCCGAGCTAAATTAC ACATTG-3';

antisense primer: 5'-CCTTGTGGAGGGATGTAC AGA-3'.

ICAM-1 sense primer: 5'-GCCTTGGTAGAGGTG ACTGAG-3';

antisense primer: 5'-GACCGGAGCTGAAAA GTTGTA-3'.

The amount of each gene was determined and normalized by the amount of $\beta$-actin.

\section{LPS-induced ALI in mice}

The 32 male C57BL/6 mice were randomly divided into four groups, on average: the control group, LPS group, 8f+LPS group, and XAN+LPS group. The mice in the $\mathbf{8 f}+\mathrm{LPS}$ and $\mathrm{XAN}+\mathrm{LPS}$ groups were oral pretreated with $\mathbf{8 f}$ (dissolved in $0.5 \% \mathrm{CMC}-\mathrm{Na}$ ) and XAN (dissolved in 0.5\% CMC-Na) at a dosage of $20 \mathrm{mg} / \mathrm{kg} /$ day, respectively, for three consecutive days. The control-Vehicle and LPS-Vehicle groups were given the same volume of $0.5 \% \mathrm{CMC}-\mathrm{Na}$. After being anesthetized by diethyl ether, the mice from the LPS, $\mathbf{8 f}+\mathrm{LPS}$, and XAN+LPS groups were intratracheally instilled with LPS $(5 \mathrm{mg} / \mathrm{kg})$ to induce lung injury. Mice were killed under ether anesthesia at $6 \mathrm{~h}$ after LPS instillation. Bronchoalveolar lavage fluid, serum, and lung tissues were collected for further tests.

\section{Histological analysis}

Lung tissues were fixed in 4\% paraformaldehyde solution, embedded in paraffin, and ectioned at $5 \mu \mathrm{m}$. After dehydration, tissues were stained with hematoxylin and eosin (H\&E) and observed with a Nikon Eclipse E800 microscope (200× amplification; Nikon). The severity of microscopic injury was graded from 0 (normal) to 4 (severe), based on the following categories: neutrophil infiltration, interstitial edema, hemorrhage, and hyalinemembrane. The sum of all scores was combined to calculate a composite score, as described previously. ${ }^{23}$ 


\section{Immunohistochemistry analysis}

Lung tissues ( $5 \mu \mathrm{m}$ thickness) were prepared, deparaffinized in xylene, and hydrated using an ethanol gradient. A pressure cooker was used for heat-induced antigen retrieval $(10 \mathrm{mM}$ sodium citrate buffer, $\mathrm{pH} 6.5$ ). After treatment with $30 \%$ of hydrogen peroxide, all sections were blocked in $5 \%$ bovine serum albumin and incubated with primary anti-F4/80 and anti-LY-6G antibody overnight at $4{ }^{\circ} \mathrm{C}$. The slides were then incubated with HRP-labeled secondary antibody for $1 \mathrm{~h}$. After the sections were incubated with 3,3-diaminobenzidine tetrahydrochloride for color development and counterstained with hematoxylin, the slides were evaluated under a microscope (200× amplification; Nikon). The percentage of F4/80 anti-LY-6G-positive inflammatory cells was calculated in five randomly chosen fields (200× amplification; Nikon) per section.

\section{Wet/dry ratio ${ }^{24}$}

The lung wet-to-dry (W/D) ratio was calculated to observe the pulmonary edema. At the end of the experiment, animals were sacrificed at $6 \mathrm{~h}$ after LPS challenge. After the middle lobe of the right lung was collected, the wet weight was recorded. Then the lung was heated in a thermostatic oven at $65^{\circ} \mathrm{C}$ for $48 \mathrm{~h}$ and weighed to determine the baseline lung dry mass levels.

\section{Protein concentration in bronchoalveolar lavage fluid (BALF)}

BALF was obtained at the end of the experimental by irrigating the left lung with saline $(4 \times 200 \mu \mathrm{L})$. This fluid was centrifuged at $1,000 \mathrm{rpm}$ for $10 \mathrm{~min}$, and the protein concentration in the supernatant was determined using a BCA protein assay (Pierce, Rockford, IL, USA).

\section{Western blot analysis}

Macrophages were pretreated with vehicle (DMSO) or the new compounds of interest at $10 \mu \mathrm{M}$ for $30 \mathrm{~min}$, followed by incubation with LPS $(0.5 \mu \mathrm{g} / \mathrm{mL})$ for $30 \mathrm{~min}$. Then, cells were lysed and total protein was collected. Bradford assay (Bio-Rad Laboratories) was used to detect the protein concentration. After balancing and transgender, protein samples were separated by $10 \%$ SDS-PAGE and transferred onto a PVDF membrane (Bio-Rad Laboratories). Membranes were blocked with 5\% milk in Tris-buffered saline containing $0.05 \%$ Tween- 20 for $1.5 \mathrm{~h}$ at room temperature. Primary antibodies were applied and membranes incubated overnight at $4^{\circ} \mathrm{C}$. The membranes were then washed in Tris-buffered Saline with Tween 20 (TBST) and reacted with secondary horseradish peroxidase-conjugated antibodies $(1: 3,000)$ for $1 \mathrm{~h}$ at room temperature. Blots were then visualized using enhanced chemiluminescence reagent (Bio-Rad Laboratories). The density of the immunoreactive bands was analyzed using ImageJ software (NIH, Bethesda, MD, USA).

\section{Statistical analysis}

Data are expressed as the mean \pm standard error of the mean (SEM). Student's $t$-test was employed to analyze the differences between sets of data. Statistics were performed using GraphPad Pro (GraphPad, San Diego, CA, USA). $P$-values less than $0.05(P<0.05)$ were considered indicative of significance. All experiments were repeated at least three times.

\section{Results and discussion Evaluation of anti-inflammatory and cytotoxic activities}

LPS is the most potent innate immune-activating stimuli in the outer membrane of Gram-negative bacteria, which induces the activation of monocytes and macrophages, resulting in the increased production of proinflammatory cytokines including TNF- $\alpha$, IL-6, and IL-12. ${ }^{25,26}$ Evidence from experimental and clinical studies shows that these proinflammatory cytokines play a significant role in accelerated inflammation-mediated ALI pathogenesis. ${ }^{27}$ All the synthesized 2-benzylidene-1-indanone derivatives were evaluated for their in vitro anti-inflammatory activity toward TNF- $\alpha$ and IL-6 release in LPS-stimulated MPMs, and XAN was used as a positive control. The macrophages were preincubated for $30 \mathrm{~min}$ with $10 \mu \mathrm{M}$ test compounds, $\mathrm{XAN}$, and DMSO, which was used as the control medium. Subsequently, the cells were incubated with LPS $(0.5 \mu \mathrm{g} / \mathrm{mL})$ for $24 \mathrm{~h}$ at $37^{\circ} \mathrm{C}$. The ability (\% inhibition) of the tested compounds to reduce proinflammatory cytokines IL- 6 and TNF- $\alpha$ by ELISA is summarized in Table 1 . The majority of these derivatives showed moderate potency against both LPS-induced expression of IL- 6 and TNF- $\alpha$, and had a pronounced increase on IL-6 expression. Notably, compound 4d, with an installment of 4-hydroxy and 3-methoxy groups at $\mathrm{R}^{1}$, exhibited the most potent effect on LPS-induced IL-6 and TNF- $\alpha$ expression, and therefore was chosen to be the lead molecule for the next structural optimization.

\section{SAR of benzene ring $B$ : identification of lead 4d}

To the best our knowledge, data are very limited about the cytokine-inhibitory effects of 2-benzylidene-1-indanone derivatives and their SAR. Compounds $\mathbf{4 a}$, with a 4'-methoxy group in the benzene ring $\mathrm{B}$, had an equivalent potency to 
Table I 2-benzylidene- I-indanone derivatives 4a-t inhibited LPS-induced IL-6 and TNF- $\alpha$ secretion in MPM

\begin{tabular}{|c|c|c|c|c|c|c|c|}
\hline \multirow[t]{2}{*}{ Compound } & \multirow[t]{2}{*}{$\mathbf{R}^{\prime}$} & \multicolumn{2}{|c|}{ (\%) Inhibition (10 $\mu \mathrm{M})^{*}$} & \multirow[t]{2}{*}{ Compound } & \multirow[t]{2}{*}{$\mathbf{R}^{\prime}$} & \multicolumn{2}{|c|}{ (\%) Inhibition (10 $\mu \mathrm{M})^{*}$} \\
\hline & & IL-6 & TNF- $\alpha$ & & & IL-6 & TNF- $\alpha$ \\
\hline $4 a$ & $4^{\prime}$-OMe & $61.61 \pm 6.21$ & $48.26 \pm 1.14$ & $4 \mid$ & $2^{\prime}-\mathrm{Cl}$ & $45.77 \pm 1.79$ & $26.36 \pm 4.99$ \\
\hline $4 b$ & $4^{\prime}-\mathrm{OEt}$ & $35.54 \pm 1.21$ & $14.42 \pm 6.14$ & $4 m$ & $2^{\prime}-\mathrm{Br}$ & $63.04 \pm 2.13$ & NA \\
\hline 4c & $3^{\prime}, 4^{\prime}-\mathrm{OH}$ & $70.32 \pm 3.27$ & $45.59 \pm 3.59$ & $4 n$ & $3^{\prime}-\mathrm{Br}$ & $47.37 \pm 6.65$ & $17.87 \pm 1.89$ \\
\hline $4 d$ & $3^{\prime}-\mathrm{OMe}, 4^{\prime}-\mathrm{OH}$ & $69.28 \pm 1.58$ & $83.73 \pm 4.05$ & 4o & $4^{\prime}-\mathrm{Br}$ & $53.7 I \pm 3.29$ & $29.40 \pm 0.61$ \\
\hline $4 e$ & $2^{\prime}, 3^{\prime}-\mathrm{OMe}$ & $41.35 \pm 1.70$ & $34.13 \pm 3.19$ & $4 p$ & $4^{\prime}-\mathrm{F}$ & $59.99 \pm 1.32$ & $41.99 \pm 1.44$ \\
\hline $4 f$ & $2^{\prime}, 4^{\prime}-\mathrm{OMe}$ & $52.29 \pm 2.09$ & $44.52 \pm 3.61$ & $4 q$ & $4^{\prime}-\mathrm{CF}_{3}$ & $52.24 \pm 5.33$ & $36.07 \pm 2.03$ \\
\hline $4 g$ & $3^{\prime}, 4^{\prime}, 5^{\prime}-\mathrm{OMe}$ & $55.69 \pm 1.63$ & $67.94 \pm 1.21$ & $4 r$ & $3^{\prime}, 4^{\prime}-\mathrm{F}$ & $|7.39 \pm| .5 \mid$ & $18.93 \pm 1.19$ \\
\hline $4 \mathrm{~h}$ & $2^{\prime}, 3^{\prime}, 4^{\prime}-\mathrm{OMe}$ & $55.33 \pm 9.97$ & $67.92 \pm 3.85$ & $4 s$ & $3^{\prime}, 4^{\prime}-\mathrm{Cl}$ & $54.08 \pm 1.13$ & $33.89 \pm 5.37$ \\
\hline $4 i$ & $2^{\prime}, 4^{\prime}, 6^{\prime}-\mathrm{OMe}$ & $54.21 \pm 1.02$ & $44.16 \pm 3.58$ & $4 t$ & $3^{\prime}-\mathrm{NO}_{2}, 4^{\prime}-\mathrm{Cl}$ & $47.37 \pm 3.16$ & $36.5 I \pm 2.91$ \\
\hline $4 j$ & $2^{\prime}, 4^{\prime}, 5^{\prime}-\mathrm{OMe}$ & $54.78 \pm 2.28$ & $28.40 \pm 1.82$ & XAN & & $62.45 \pm 1.83$ & $53.27 \pm 1.65$ \\
\hline $4 k$ & $2^{\prime}-F$ & $41.28 \pm 1.98$ & $15.68 \pm 3.64$ & & & & \\
\hline
\end{tabular}

Notes: Macrophages were plated at a density of $5.0 \times 10^{5} /$ plate at $37^{\circ} \mathrm{C}$ and $5 \% \mathrm{CO}_{2}$ overnight. Cells were pretreated with vehicle and compounds $(10 \mu \mathrm{M})$ for 30 min, and subsequently treated with LPS $(0.5 \mu \mathrm{g} / \mathrm{mL})$ for $24 \mathrm{~h}$. The culture media were collected and the inflammatory cytokines, TNF- $\alpha$ and IL-6, in media were detected by ELISA and normalized by total protein concentration. *Values are the mean of at least $n=3$ independent experiments \pm SEM.

Abbreviations: IL-6, interleukin-6; LPS, lipopolysaccharide; TNF- $\alpha$, tumor necrosis factor- $\alpha$; MPM, murine primary macrophage; ELISA, enzyme-linked immunosorbent assay; NA, no activity; XAN, xanthohumol; SEM, standard error of the mean.

XAN in either IL-6 or TNF- $\alpha$. The increasing size of the C-4' substituents from the methoxy to the ethyl group (4b) significantly decreased both IL- 6 and TNF- $\alpha$ inhibitory properties from $61.61 \%$ (for IL-6), $48.6 \%$ (for TNF- $\alpha$ ) for compound 4a to $35.54 \%$ (for IL-6), and $14.42 \%$ (for TNF- $\alpha$ ), indicating that a larger alkoxy group at this position was not welltolerated in the anti-inflammatory activity. Incorporation of $3^{\prime}, 4^{\prime}$-hydroxy groups in the benzene ring B yields compound $\mathbf{4 c}$, which exhibited a significant gain in the IL-6 inhibitory profile (\% Inhibition $=69.28 \%$ ) compared to compound $\mathbf{4 a}$. Methylation of the 3 -hydroxy group of compounds $4 \mathbf{c}$ led to compound $\mathbf{4 d}$, which was equipotent in IL-6 inhibition with $\mathbf{4 c}$, and resulted in an approximate 1.8-fold increase in TNF- $\alpha$ activity. This indicates that a methoxy group at this position is preferred for the activity. Disappointedly, introduction of di- or trimethoxy groups on ring B yielded compounds $4 \mathbf{e}$ ( $2^{\prime}, 3^{\prime}$-methoxy), $4 \mathbf{f}$ (2', $4^{\prime}$-methoxy), $\mathbf{4 g}\left(3^{\prime}, 4^{\prime}, 5^{\prime}\right.$-methoxy), 4h ( $\left(2^{\prime}, 3^{\prime}, 4^{\prime}\right.$-methoxy), 4i (2', 4', $6^{\prime}$-methoxy), and $4 \mathbf{j}$ ( $2^{\prime}$, $4^{\prime}, 5^{\prime}$-methoxy), which exhibited a dramatic decrease in their IL- 6 or TNF- $\alpha$ inhibitory activity, with inhibitory rate values ranging from $26.47 \%$ to $67.94 \%$. Comparatively, electron-withdrawing substituted compounds exhibited very weak or no activity. For example, about one- and three-fold lower IL- 6 and TNF- $\alpha$ inhibitory profiles were observed for $\mathbf{4 k}-\mathbf{4 t}$, respectively, compared to the control XAN, and, in particular, compound 4r (3', $4^{\prime}$-fluoro) expressed the weakest anti-inflammatory capacity $(17.39 \%$ and $18.93 \%$ inhibitory rates for IL- 6 and TNF- $\alpha$, respectively). This suggests that mono- or di-substitution of electron-withdrawing functional groups on benzene ring B is not tolerated.

\section{Optimization at the benzene ring $A$ of $\mathrm{I}$-indanone to obtain $\mathbf{8 f}$}

To further improve the anti-inflammatory activity and, in particular, inhibition on IL-6, we next directed our optimization effort to modify the benzene ring A of $\mathbf{4 d}$ by introducing different types of groups. These results are shown in Table 2. Incorporation of hydroxyl group at the 7- and 5-position of benzene ring A led to compounds $\mathbf{8 a}$ and $\mathbf{8 b}$, which, respectively, showed either markedly reduced or no activity. Interestingly, methoxylated compounds 8c-8e displayed almost equal IL- 6 and TNF- $\alpha$ inhibitory activity to that of $\mathbf{8 a}$. However, to our surprise, compound 8f, with a 5-, 6-dimethoxyl substitution at ring A displayed the most promising effect on LPS-induced IL- 6 and TNF- $\alpha$ production, with its inhibitory rates reaching $81.41 \%$ and $79.29 \%$, respectively. Meanwhile, etherification at the 4-, 5-, 6-, or 7-hydroxyl group with $O$-propyl or $O$-isopropyl moieties produced compounds $\mathbf{8 g - 8 n}$. All of the compounds, except for $\mathbf{8 h}, \mathbf{8 m}$, and $\mathbf{8 n}$, had marked improvement in blocking TNF- $\alpha$ production, with 
Table 2 2-benzylidene- I-indanone derivatives 8a-s inhibited LPS-induced IL-6 and TNF- $\alpha$ secretion in MPM<smiles>COc1cc(/C=C2\Cc3ccccc3C2=O)ccc1O</smiles>

\begin{tabular}{|c|c|c|c|c|c|c|c|c|c|}
\hline \multirow[t]{2}{*}{ Compound } & \multirow[t]{2}{*}{$\mathbf{R}^{2}$} & \multicolumn{2}{|c|}{ (\%) Inhibition (10 $\mu \mathrm{M})^{*}$} & \multirow{2}{*}{$\frac{\text { HL7702 cell }}{\text { Survival rate (\%) }}$} & \multirow[t]{2}{*}{ Compound } & \multirow[t]{2}{*}{$\mathbf{R}^{2}$} & \multicolumn{2}{|c|}{ (\%) Inhibition ( $10 \mu \mathrm{M})^{*}$} & \multirow{2}{*}{$\frac{\text { HL7702 cell }}{\text { Survival rate (\%) }}$} \\
\hline & & IL-6 & TNF- $\alpha$ & & & & IL-6 & TNF- $\alpha$ & \\
\hline$\overline{4 d}$ & $6-\mathrm{OH}$ & $69.12 \pm 4.29$ & $80.80 \pm 3.33$ & $77.43 \pm 3.69$ & $8 j$ & 4-OPr & $69.13 \pm 1.76$ & $41.63 \pm 1.38$ & $93.96 \pm 7.95$ \\
\hline $8 a$ & $7-\mathrm{OH}$ & $40.00 \pm 1.65$ & $44.65 \pm 1.31$ & $84.92 \pm 4.16$ & $8 \mathbf{k}$ & 7-O(i-Pr) & $83.17 \pm 0.60$ & $62.85 \pm 1.05$ & $70.03 \pm 7.54$ \\
\hline $8 b$ & $5-\mathrm{OH}$ & $17.15 \pm 2.77$ & NA & $82.68 \pm 5.95$ & 81 & 6-O(i-Pr) & $78.45 \pm 1.46$ & $56.85 \pm 7.76$ & $89.64 \pm 6.97$ \\
\hline $8 c$ & 6-OMe & $50.07 \pm 4.14$ & $37.7 I \pm 1.65$ & $96.36 \pm 3.84$ & $8 m$ & 5-O(i-Pr) & $62.53 \pm 4.05$ & $16.67 \pm 4.75$ & $97.62 \pm 1.87$ \\
\hline 8d & 5-OMe & $40.04 \pm 1.60$ & $48.27 \pm 2.33$ & $98.31 \pm 1.92$ & $8 n$ & 4-O(i-Pr) & $49.99 \pm 1.77$ & $35.92 \pm 2.38$ & $75.6 I \pm 5.7 I$ \\
\hline $8 \mathrm{e}$ & 4-OMe & $56.36 \pm 2.05$ & $60.27 \pm 2.04$ & $82.75 \pm 4.23$ & 80 & $6-\mathrm{N}(\mathrm{Et})_{2}$ & $50.05 \pm 4.75$ & $29.12 \pm 2.48$ & $85.90 \pm 6.81$ \\
\hline $8 f$ & 5,6-OMe & $8 I .4 I \pm 3.68$ & $79.29 \pm 2.55$ & $91.09 \pm 1.12$ & $8 p$ & $6-\mathrm{N}\left(-\mathrm{CH}_{2}-\right)_{4}$ & $74.1 I \pm 3.6 I$ & $68.93 \pm 0.99$ & $96.47 \pm 3.13$ \\
\hline $8 g$ & 7-OPr & $84.92 \pm 1.10$ & $71.99 \pm 0.88$ & $74.06 \pm 4.28$ & $8 q$ & $6-\mathrm{N}\left(-\mathrm{CH}_{2}-\right)_{5}$ & $69.7 I \pm 2.32$ & $39.14 \pm 3.27$ & $99.01 \pm 2.03$ \\
\hline $8 \mathrm{~h}$ & 6-OPr & $57.74 \pm 5.84$ & $55.36 \pm 6.48$ & $97.00 \pm 1.69$ & $8 r$ & $6-\mathrm{N}\left(-\mathrm{CH}_{2}-\right)_{6}$ & $62.50 \pm 4.48$ & $56.37 \pm 4.22$ & $98.58 \pm 8.14$ \\
\hline $8 \mathrm{i}$ & 5-OPr & $76.62 \pm 2.67$ & NA & $92.83 \pm 6.16$ & $8 \mathrm{~s}$ & 6-NH-COMe & $18.60 \pm 2.88$ & $24.78 \pm 1.66$ & $85.85 \pm 1.65$ \\
\hline
\end{tabular}

Notes: Macrophages were plated at a density of $5.0 \times 10^{5} /$ plate at $37^{\circ} \mathrm{C}$ and $5 \% \mathrm{CO}_{2}$ overnight. Cells were pretreated with vehicle and compounds ( $\left.10 \mu \mathrm{M}\right)$ for 30 min, and subsequently treated with LPS $(0.5 \mu \mathrm{g} / \mathrm{mL})$ for $24 \mathrm{~h}$. The culture media were collected and the inflammatory cytokines, TNF- $\alpha$ and IL-6, in media were detected by ELISA and normalized by total protein concentration. *Values are the mean of at least $n=3$ independent experiments \pm SEM.

Abbreviations: IL-6, interleukin-6; LPS, lipopolysaccharide; TNF- $\alpha$, tumor necrosis factor- $\alpha$; MPM, murine primary macrophage; ELISA, enzyme-linked immunosorbent assay; NA, no activity; SEM, standard error of the mean.

inhibitory rates ranging from $69.13 \%$ (for $\mathbf{8 j}$ ) to $84.92 \%$ (for $\mathbf{8 g}$ ), but most of these compounds (except for $\mathbf{8 g}$ ) exhibited dramatically reduced 1.3-5-fold IL-6 inhibition compared with that of $\mathbf{4 d}$. This result indicates that the three-carbon chain alkoxy groups at the $\mathrm{C}-7$ position (for $\mathbf{8 g}$ and $\mathbf{8 k}$ ) were beneficial to the activity. Further screening of substituents around $\mathbf{4 d}$ revealed that incorporation of various substituted amino groups at the o-position on the phenyl ring provided

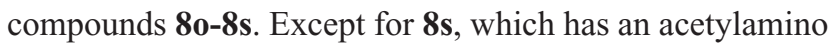

group on the benzene ring, these compounds exhibited a significantly decreased anti-inflammatory ability $(18.60 \%$ and $24.78 \%$, for IL-6 and TNF- $\alpha$, respectively). All other derivatives, including those with different size of diethylamino $(\mathbf{8 o})$, butylamine (8p), pentenylamino (8q), and hexylamino (8r) groups, displayed comparable IL-6 but diminished TNF- $\alpha$ inhibitory activities compared to $4 \mathbf{d}$. Illustration of the structure-activity relationship of these 2-benzylidene-1indanone derivatives is presented in Figure 2.

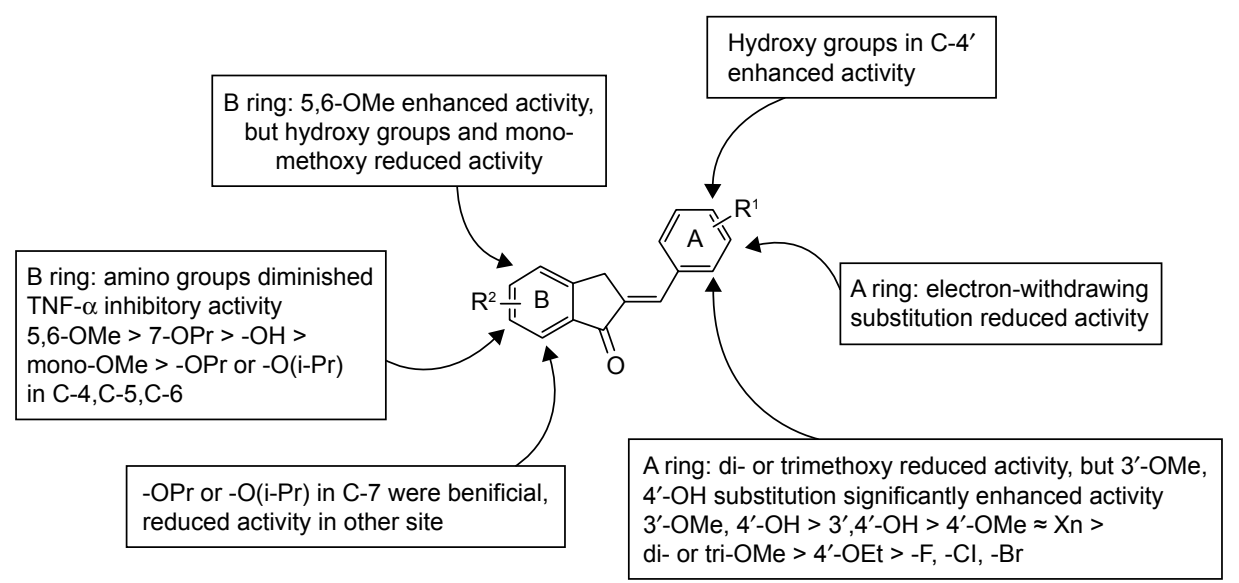

Figure 2 Structure-activity relationships of 2-benzylidene- I-indanone derivatives. Anti-inflammatory activity was measured as inhibition on LPS-induced IL-6 and TNF- $\alpha$ production.

Abbreviations: IL-6, interleukin-6; LPS, lipopolysaccharide; TNF- $\alpha$, tumor necrosis factor- $\alpha$. 
Before further bioactivity evaluation, derivatives 8a-8s and $\mathbf{4 d}$ were tested for their cytotoxicity and safety in the human normal hepatic cell line, HL-7702, by MTT after treatment of the cells for $24 \mathrm{~h}$ with compounds at a concentration of $10 \mu \mathrm{M}$. As shown in Table 2, all of these compounds showed no significant toxicity in hepatic cells, indicating that they are relatively safe.

\section{Active compounds inhibit LPS-induced cytokines release in a dose-dependent} manner

To further confirm the anti-inflammatory effect of synthetic 2-benzylidene-1-indanone derivatives in vitro, the most promising compounds $\mathbf{4 d}, \mathbf{8 f}$, and $\mathbf{8 g}$ were selected to assess dose-dependent inhibitory effects against LPS-induced TNF- $\alpha$ and IL- 6 release. MPMs were pretreated with compounds in a series of concentrations $(1.25,2.5,5$, and $10 \mu \mathrm{M})$ for $30 \mathrm{~min}$ and were subsequently incubated with LPS $(0.5 \mu \mathrm{g} / \mathrm{mL})$ for $24 \mathrm{~h}$. The release of IL- 6 and TNF- $\alpha$ was determined by ELISA. As shown in Figure 3A and B, compounds 4d, 8f, 8g, and XAN exhibited dose-dependent inhibition on both TNF- $\alpha$ and IL- 6 release stimulated by LPS. Compound $\mathbf{8 f}$ showed the strongest inhibition against the expression of both IL- 6 and TNF- $\alpha$. These results further support the potential of these compounds as antiinflammatory agents.
A

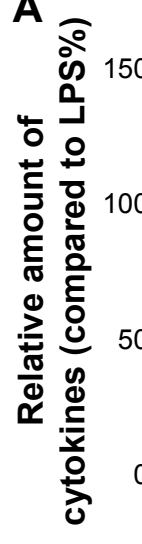

TNF- $\alpha$

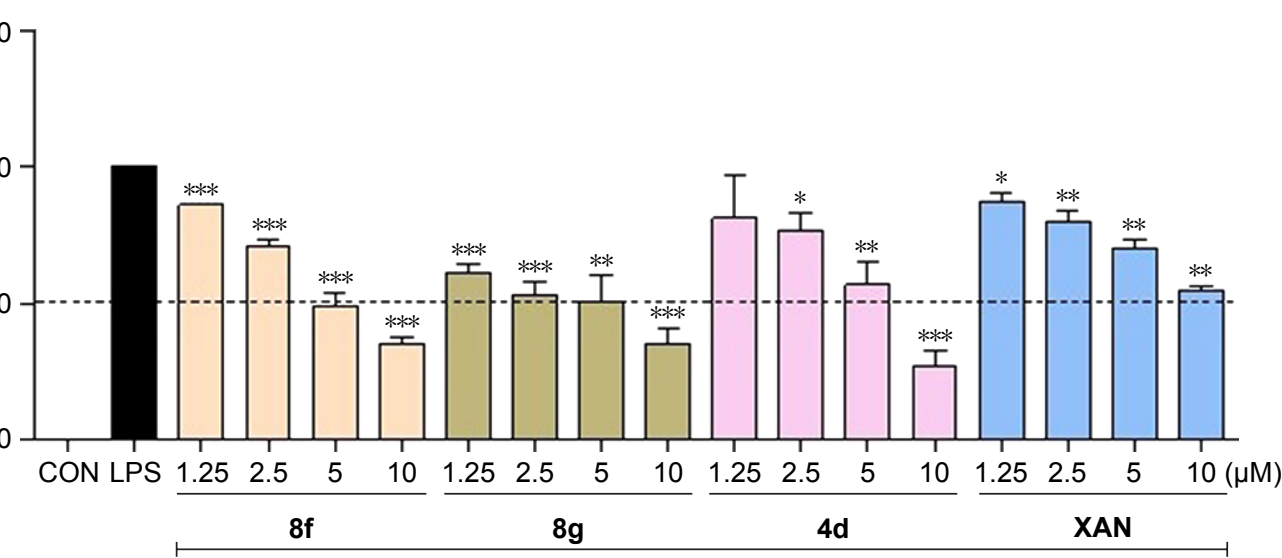

LPS $0.5 \mu \mathrm{g} / \mathrm{mL}$

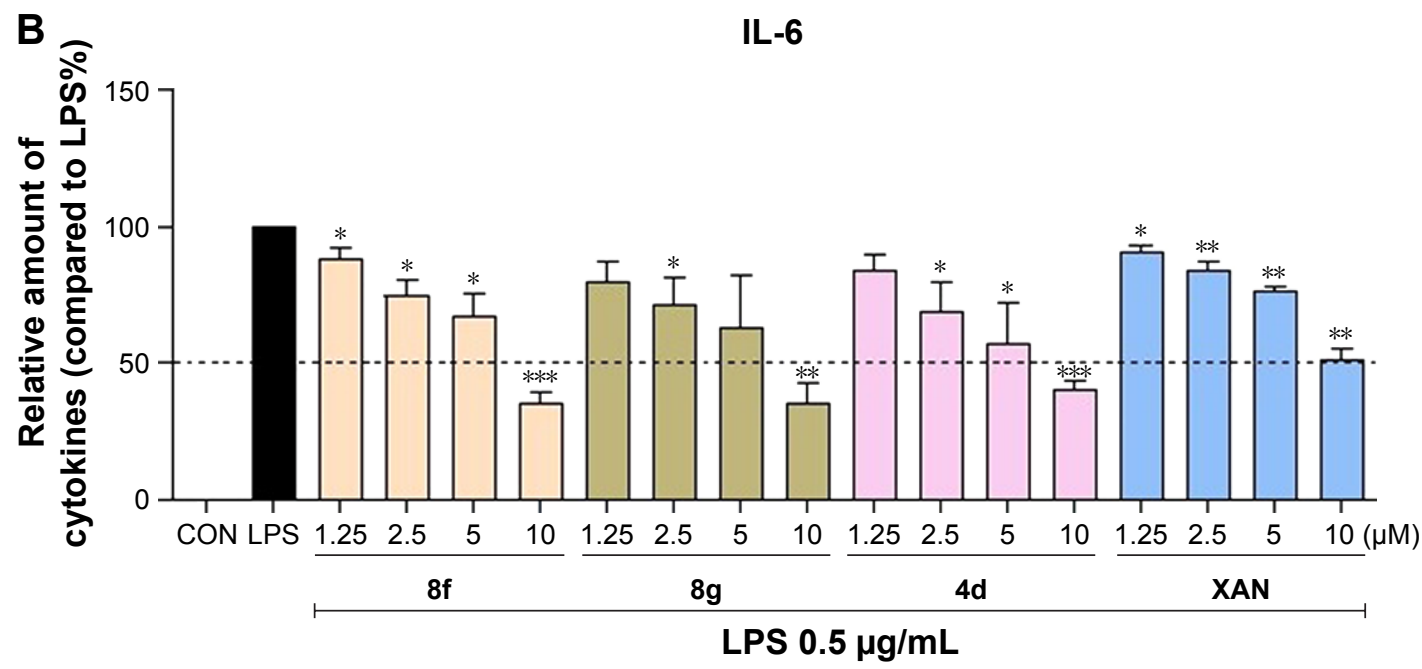

Figure 3 Compounds $\mathbf{8 f}, \mathbf{8 g}, \mathbf{4 d}$, and XAN inhibited LPS-induced IL-6 release in a dose-dependent manner. MPMs were plated at a density of 5.0×I05/plate overnight in $37^{\circ} \mathrm{C}$ and $5 \% \mathrm{CO}_{2}$. Cells were pretreated with compounds in a series concentration of $1.25,2.5,5$, and $10 \mu \mathrm{M}$ for 30 min and subsequently incubated with or without LPS $(0.5 \mu \mathrm{g} / \mathrm{mL})$ for $24 \mathrm{~h}$. (A) TNF- $\alpha$ and (B) IL-6 levels in the culture medium were measured by ELISA and were normalized by the total protein. The results were presented as the percentage of LPS control. Each bar represents the mean \pm SEM of the three independent experiments. Statistical significance relative to the LPS group was indicated, $* P<0.05 ; * * P<0.01$, *** $P<0.001$.

Abbreviations: XAN, xanthohumol; LPS, lipopolysaccharide; TNF- $\alpha$, tumor necrosis factor- $\alpha$; MPMs, murine primary macrophages; ELISA, enzyme-linked immunosorbent assay; SEM, standard error of the mean; CON, control group. 


\section{Active compounds suppressed mRNA expressions in LPS-stimulated macrophages}

To determine whether the decrease in LPS-induced macrophages might be associated with transcriptional inhibition, messenger RNA (mRNA) levels of TNF- $\alpha$, IL-6, IL-1 $\beta$, and intercellular adhesion molecule 1 (ICAM-1) were measured by a real-time quantitative PCR (RT-qPCR) method. Macrophages were treated with LPS $(0.5 \mu \mathrm{g} / \mathrm{mL})$ for $6 \mathrm{~h}$ and examined for the expression of proinflammatory genes with or without compounds $\mathbf{4 d}, \mathbf{8 f}$, or $\mathbf{8 g}$ as treatment. The results, summarized in Figure 4A-D clearly demonstrate that the mRNA levels of TNF- $\alpha$, IL-6, IL-1 $\beta$, and ICAM- 1 were all upregulated by LPS incubation. Except for the inhibitory effects against IL-1 $\beta$, pretreatment with the three compounds effectively downregulate the expressions of TNF- $\alpha$, IL-6, IL-1 $\beta$, and ICAM-1 with statistical significance. In particular, compound $\mathbf{8 f}$ was the most active compound in inhibiting mRNA expressions of those inflammatory mediators. Subsequently, we used ELISA to analyze the effect of active compounds on the production of TNF- $\alpha$ and IL- 6 in cell lysates after LPS challenge. As shown in Figure 4E and F, compounds $\mathbf{4 d}, \mathbf{8 f}, \mathbf{8 g}$, and XAN significantly reduced the production of TNF- $\alpha$ and IL-6, compared with the LPS group. These data provide evidence for the anti-inflammatory effect of 2-benzylidene-1-indanones $\mathbf{4 d}, \mathbf{8 f}$, and $\mathbf{8 g}$, which partly affect the cytokine profile at the mRNA level.

\section{Effects of $\mathbf{8 f}$ on LPS-induced lung pathophysiologic changes in ALI mice}

LPS has been used extensively to induce animal models of ALI, which closely resembles human ALI. LPS-induced ALI is characterized by rapid alveolar injury, vascular leakage, lung inflammation, neutrophil accumulation, and induced cytokines production, leading to lung edema. ${ }^{28}$ To investigate the possible mechanism underlying the protective effect of 2-benzylidene-1-indanone derivatives, we further determined the concentration of total protein, inflammatory cell count, inflammatory mediator count, lung W/D ratio, and neutrophil count, to evaluate whether the representative compounds were able to relieve lung injury in the BALF of LPS-induced ALI mice. Compound 8f, which demonstrated the highest activities and low cytotoxicity, was selected for this study. The details of animal experiments were described in the experimental section.

The results in Figure 5 indicated that total cells (Figure 5A), total protein concentration (Figure 5B), lung W/D ratio (Figure 5C), and neutrophils (Figure 5D) significantly increased in the BALF of ALI mice after LPS challenge, compared to those of the control group. Pretreatment with 8 f or XAN at $20 \mathrm{mg} / \mathrm{kg}$ was found to significantly decrease the relative amount of cells, neutrophils, and the total protein concentration compared with the LPS group, and also slightly inhibited the lung W/D ratio in BALF. We also determined TNF- $\alpha$ and IL- 6 levels in the blood and tissues
A

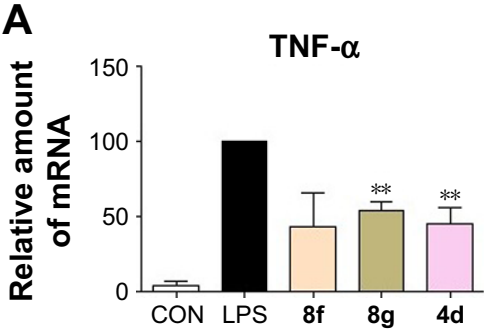

D

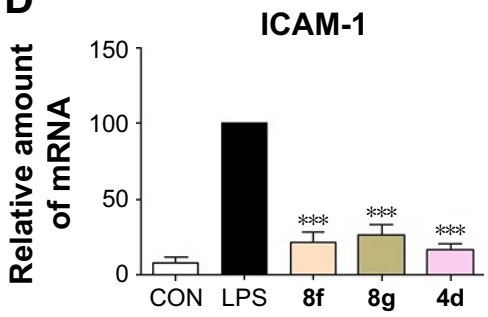

B

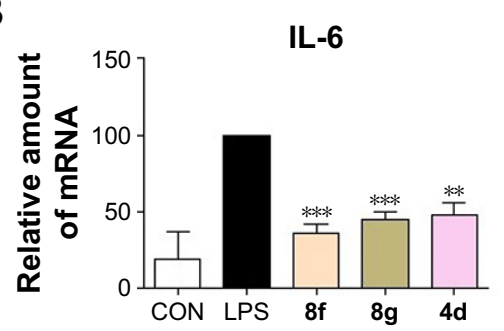

E

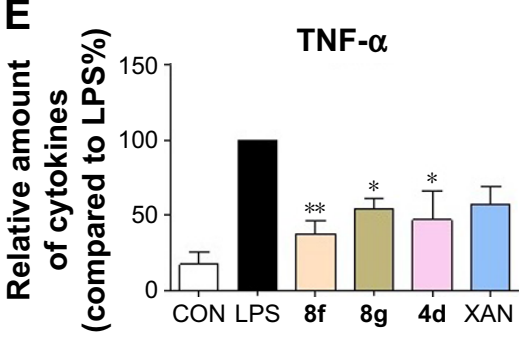

C

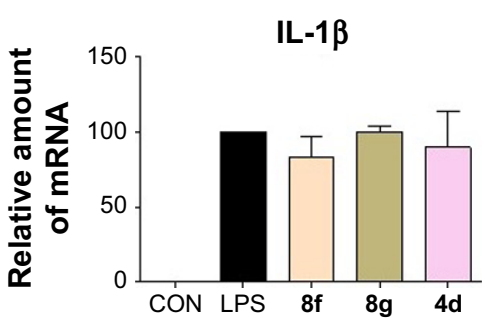

$F$

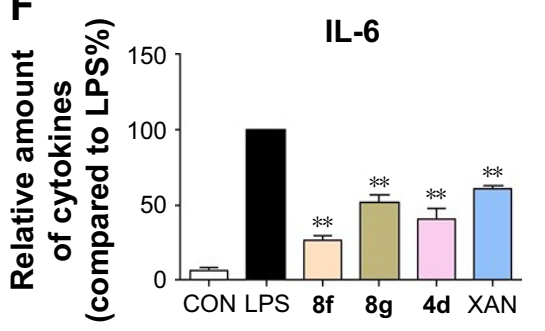

Figure 4 Active compounds inhibited the inflammatory genes expression and intracellular inflammatory factor by LPS. The mRNA levels of the inflammatory mediators (A) TNF- $\alpha$, (B) IL-6, (C) IL-I $\beta$, and (D) ICAM-I were quantified by RT-qPCR. The mRNA values for each gene were normalized to internal control $\beta$-actin mRNA and were expressed as a ratio to LPS. Each bar represents mean \pm SEM of three to five independent experiments. (E) The cell lysate level of the cytokine TNF- $\alpha$. (F) The cell lysate level of the cytokine IL-6. Statistical significance relative to LPS group was indicated, $* P<0.05$, $* * P<0.0$ I, $* * * P<0.001$.

Abbreviations: IL-6, interleukin-6; LPS, lipopolysaccharide; BALF, bronchoalveolar lavage fluid; TNF- $\alpha$, tumor necrosis factor- $\alpha$; ICAM-I, intercellular adhesion molecule I; RT-qPCR, real-time quantitative PCR; SEM, standard error of the mean; CON, control group; XAN, xanthohumol. 
A

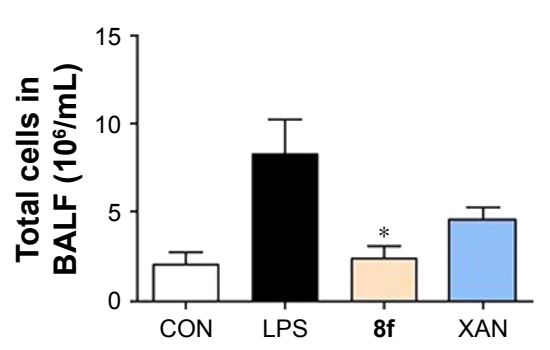

D

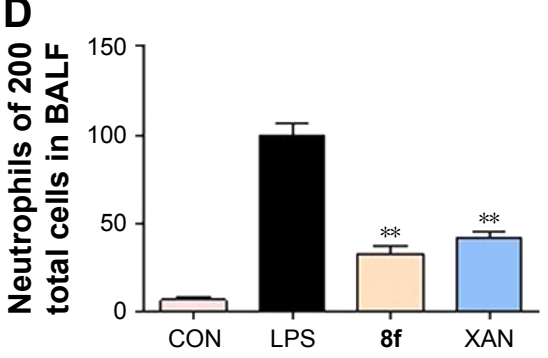

B

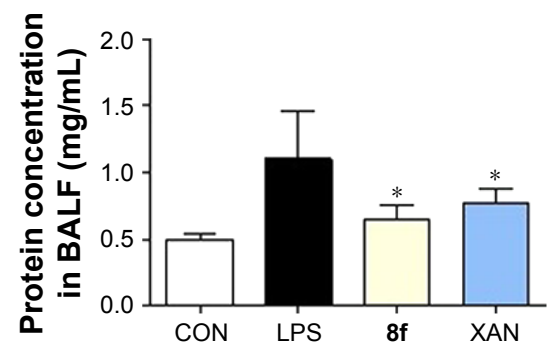

E

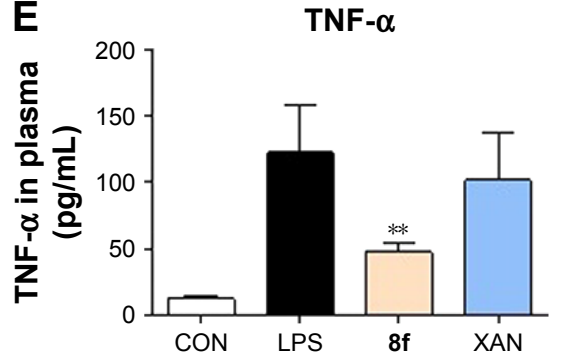

C

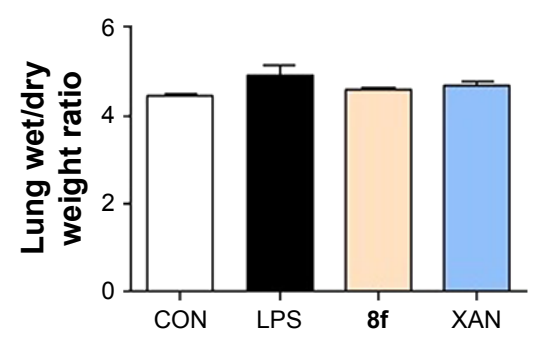

F IL-6

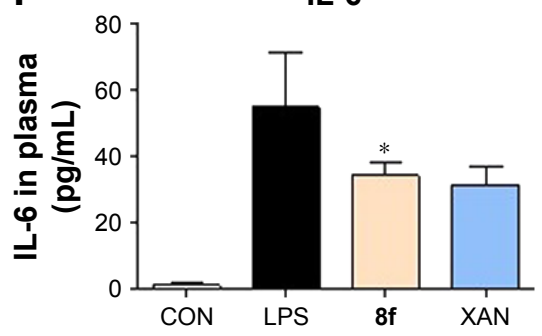

G

TNF- $\alpha$

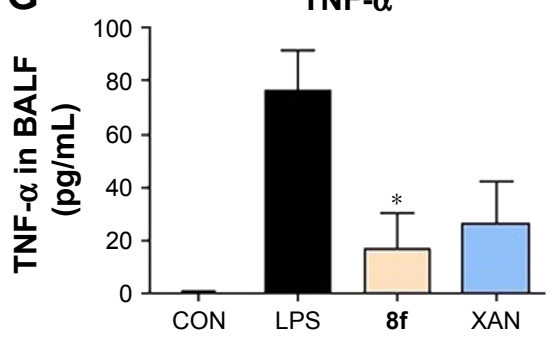

H

IL-6

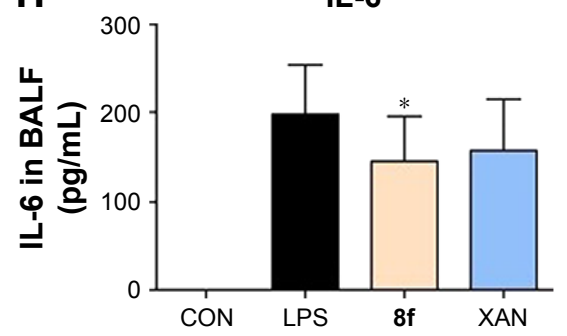

Figure $\mathbf{5} \mathbf{8 f}$ and XAN attenuate the LPS-induced ALI in mice. Mice were administrated with $\mathbf{8}$ and XAN for three consecutive days before given intratracheal instillation of LPS, $6 \mathrm{~h}$ later mice were anesthetized and killed. Bronchoalveolar lavage fluid and lung tissues were collected for further tests. (A) Total amount of cells in BALF. (B) Protein concentration in BALF. (C) W/D ratio. (D) The number of neutrophils in BALF. (E) Serum level of the cytokine TNF- $\alpha$. (F) Serum level of the cytokine IL-6. (G) BALF level of the cytokine TNF- $\alpha$. (H) BALF level of the cytokine IL-6. Statistical significance relative to the LPS group was indicated, $n \geq 5, * P<0.05$, $* * P<0.01$.

Abbreviations: XAN, xanthohumol; LPS, lipopolysaccharide; ALI, acute lung injury; BALF, bronchoalveolar lavage fluid; W/D, wet/dry; TNF- $\alpha$, tumor necrosis factor- $\alpha$; CON, control group.

of LPS-induced ALI mice. As shown in Figure 5E and F, serum TNF- $\alpha$ and IL-6 levels after LPS injection were significantly elevated in comparison with the control group, while pretreatment with $\mathbf{8 f}$ markedly prevented such increases. Oppositely, XAN treatment has no significant statistical difference in inhibiting LPS-induced TNF- $\alpha$ and IL- 6 activities. To further evaluate the anti-inflammatory actions of $\mathbf{8 f}$, levels of cytokines TNF- $\alpha$ and IL- 6 were measured in BAL fluid collected from ALI mice. As illustrated in Figure 5G and $\mathrm{H}, \mathrm{TNF}-\alpha$ and IL- 6 were all elevated in BAL fluid in response to LPS challenge compared with native mice. Treatment with $\mathbf{8 f}$ alone significantly decreased the levels of cytokines TNF- $\alpha$ and IL-6, but no statistical difference was observed in the XAN treatment group. The results indicated that $\mathbf{8 f}$ has a remarkable protective effect on LPS-induced ALI in mice.

\section{Compound $8 \mathrm{f}$ ameliorated} histopathological changes and reduced mRNA levels in lung tissues of

\section{LPS-induced ALI mice}

To verify the inhibitory effect of $\mathbf{8 f}$ against macrophage infiltration into the lung tissue, we further performed immunohistochemistry analysis with F4/80 and LY-6G, which are macrophage and neutrophils markers. ${ }^{28,29}$ As shown in Figure 6A and C, LPS alone induced a significant infiltration of F4/80 and LY-6G-positive macrophages and neutrophils in the lung sections. In contrast, macrophage and neutrophils infiltration were significantly ameliorated after treatment with 8f $(20 \mathrm{mg} / \mathrm{kg}$ ) and the positive control (XAN, $20 \mathrm{mg} / \mathrm{kg}$ ). Subsequently, we evaluated histological changes after $\mathbf{8 f}$ treatment in LPS-challenged mice by H\&E staining (Figure 6B). 
A

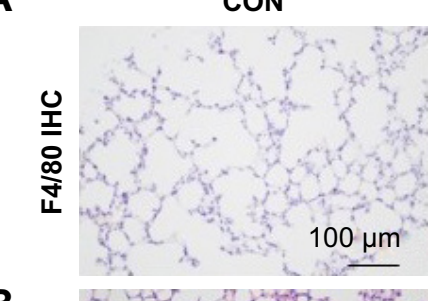

B

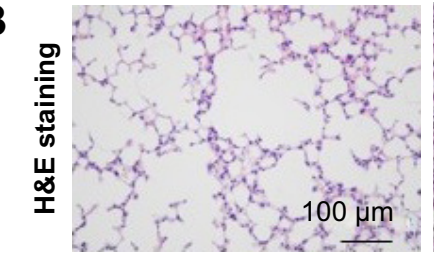

C

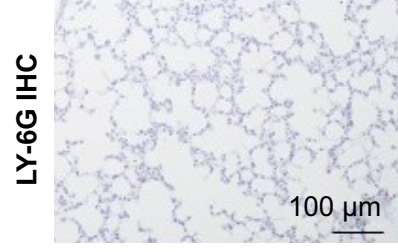

LPS

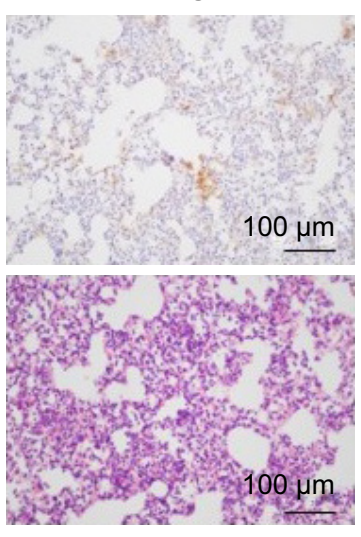

LPS+8f $(20 \mathrm{mg} / \mathrm{kg})$

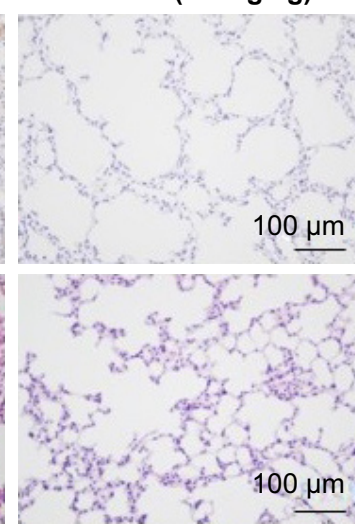

LPS+XAN (20 mg/kg)

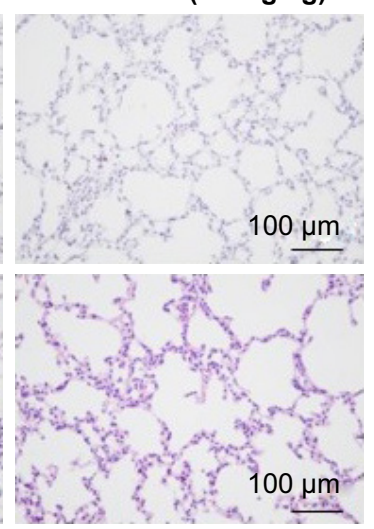

$100 \mu \mathrm{m}$
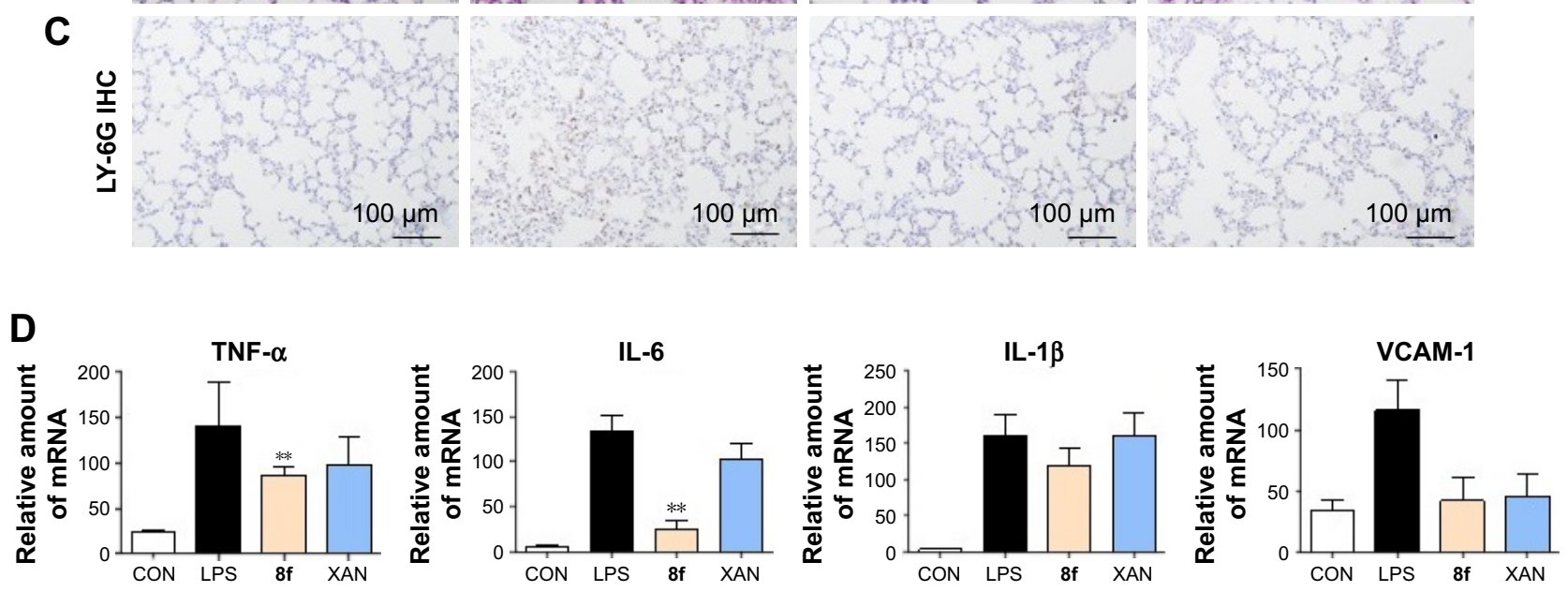

Figure 6 The 8 f and XAN inhibited macrophages in filtration through F4/80-staining, LY-6G-staining, ameliorated histopathological changes, and inflammatory gene expression in lung tissue of LPS-stimulated ALI mice. (A) F4/80 immunohistochemical staining. (B) H\&E staining. (C) LY-6G immunohistochemical staining. (D) The mRNA levels of the inflammatory mediators TNF- $\alpha$, IL-6, IL-I $\beta$, and VCAM-I. Statistical significance relative to the LPS group was indicated, $n \geq 5, * * P<0.01$.

Abbreviations: XAN, xanthohumol; IL-6, interleukin-6; LPS, lipopolysaccharide; ALI, acute lung injury; H\&E, hematoxylin and eosin; VCAM-I, vascular cell adhesion molecule I; TNF- $\alpha$, tumor necrosis factor- $\alpha$; CON, control group.

Lung tissues from the control group showed a normal structure and no histopathological change under a light microscope. LPS instillation resulted in marked pathologic changes, such as inflammatory cell infiltration, interalveolar septal thickening, and interstitial edema. However, these pathological changes induced by LPS were remarkably ameliorated by $20 \mathrm{mg} / \mathrm{kg}$ of XAN treatment, whereas an even more obvious pathological amelioration became visible in the treatment with $20 \mathrm{mg} / \mathrm{kg} \mathrm{8f}$. These results were consistent with our previous F4/80 and LY-6G staining analysis, which showed that $\mathbf{8 f}$ had a remarkable protective effect on LPS-induced histopathological changes in a mice model of ALI.

LPS exposure also elevated the mRNA levels of inflammatory cytokines in mice lung tissues. Therefore, we next investigated the inhibitory effect of compounds $\mathbf{8 f}$ on mRNA abundance for important proinflammatory factors, including TNF- $\alpha$, IL-6, IL-1 $\beta$, and VCAM-1. As shown in Figure 6D, LPS stimulated a marked increase in the accumulation of cytokine mRNAs. Except for the inhibitory effects against IL- $1 \beta$ and VCAM- 1,8 f at $20 \mathrm{mg} / \mathrm{kg}$ was found to effectively downregulate the expressions of TNF- $\alpha$ and IL-6, with statistical significance. Meanwhile, injection with $\mathbf{8 f}$ resulted in more potently reduced mRNA expressions of those inflammatory mediators compared to those injected with $\mathrm{XAN}$ at the same concentration. These data showed that antiinflammatory compound $\mathbf{8 f}$ partly affects the cytokine profile at the mRNA level. Our studies reveal that 2-benzylidene1-indanone derivatives are promising anti-inflammatory agents and should be further developed as candidates for the treatment of acute inflammatory diseases.

\section{Compound $\mathbf{8 f}$ inhibited the LPS-induced activation of NF- $\kappa B / M A P K$ signaling pathway}

In addition, to clarify the mechanism of anti-inflammatory effects of the most active compound $\mathbf{8 f}$, we attempted to 

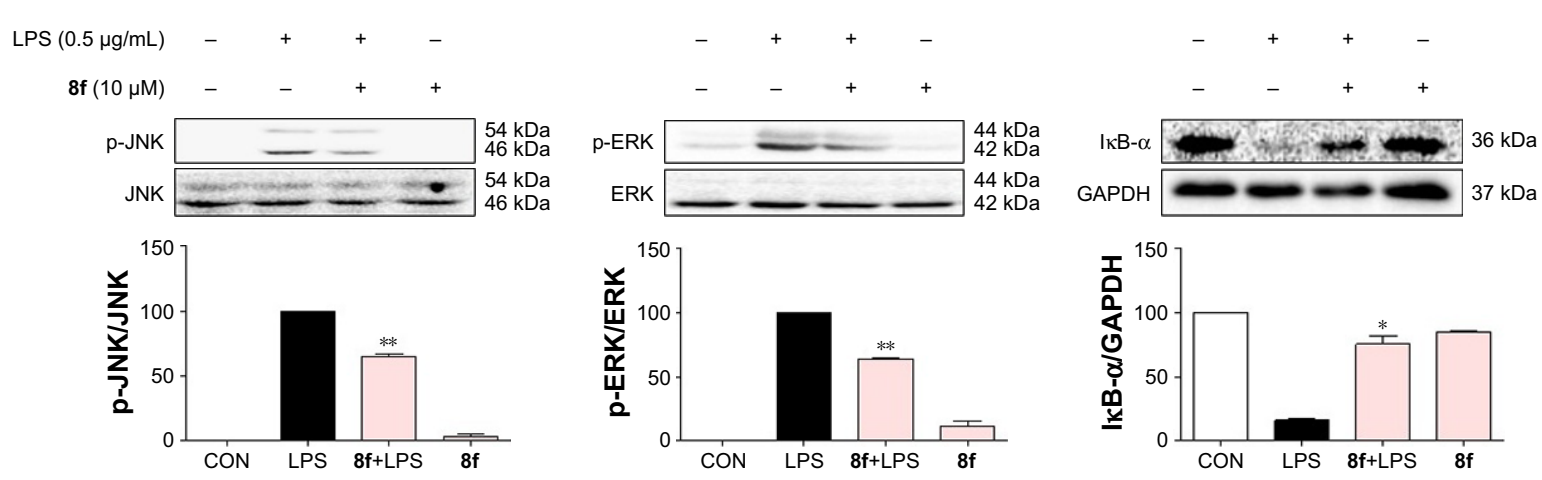

Figure $\mathbf{7}$ Effects of compound $\mathbf{8}$ f on the LPS-induced activation of NF-KB and MAPK signaling pathway. MPMs pretreated with vehicle or compound $\mathbf{8 f}$ (I0 $\mu$ M) for 30 min followed by incubation with LPS $(0.5 \mu \mathrm{g} / \mathrm{mL})$ for $20 \mathrm{~min}$. The protein levels of IKB- $\alpha$, p-JNK, JNK, p-ERK, ERK, and GAPDH were measured by immunoblot analysis. Statistical significance relative to the LPS group was indicated, $\mathrm{n} \geq 5, * P<0.05, * * p<0.0$ I.

Abbreviations: LPS, lipopolysaccharide; MPMs, murine primary macrophages; CON, control group.

identify the possible pathways responsible for the production of proinflammatory cytokines that are inhibited by our $8 \mathbf{f}$ compound. NF- $\mathrm{KB}$ and MAPK (mainly JNK, and ERK) signaling pathways have been recently shown to play important roles in regulating LPS-induced acute inflammation responses in vitro and in vivo. ${ }^{30,31}$ We investigated the possible mechanisms of NF- $\mathrm{KB} / \mathrm{MAPK}$ signaling in the anti-inflammatory action of $\mathbf{8 f}$. While in an inactivated state, NF- $\mathrm{KB}$ is located in the cytosol complexed with the

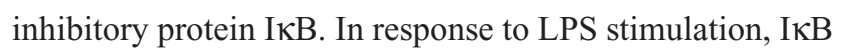
kinase $\beta$ phosphorylates cytoplasmic IкB- $\alpha$; this phospho-

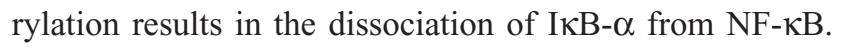
The activated NF- $\mathrm{KB}$ will translocate from the cytoplasm to nucleus and promotes the transcription of inflammatory genes. Activation of NF- $\mathrm{\kappa B}$ is regulated by the degradation of the IKB- $\alpha$; thus, we evaluated the effects of the analog on IKB- $\alpha$ degradation in LPS-stimulated MPMs.

As shown in Figure 7, 8 effectively reduced LPS-induced I $\kappa \mathrm{B}-\alpha$ degradation at a concentration of $10 \mu \mathrm{M}$. Regarding MAPK signaling, administration of LPS for 20 min induced a significant phosphorylation of ERK and JNK, respectively, while pretreatment with compound $\mathbf{8 f}$ reversed LPS-induced MAPK phosphorylation in the MPMs. These results suggest that the inhibition of NF-KB/MAPK activation may mediate the anti-inflammatory effects of $\mathbf{8 f}$.

\section{Conclusion}

In summary, a total of 39 new 2-benzylidene-indanone derivatives were designed, synthesized, and evaluated as antiinflammatory agents for the treatment of ALI. In in vitro ELISA assays, a majority of these compounds exhibited significant anti-inflammatory activities, and the most potent, $\mathbf{4 d}$, $\mathbf{8 f}$, and $8 \mathrm{~g}$, showed dose-dependent inhibition of LPS-induced TNF- $\alpha$ and IL- 6 releases in MPMs. The preliminary SAR analyses suggested that mono- or di-substitution of electronwithdrawing functional groups on benzene ring B were not tolerated, but incorporation of the three-carbon chain alkoxy groups at the C-7 position of ring A was beneficial to the activity. The in vivo experiment reveals that three active compounds, especially $\mathbf{8 f}$, could effectively inhibit the mRNA levels of multiple inflammatory cytokines in LPS-induced MPMs. Furthermore, pretreatment with active compound $\mathbf{8 f}$ significantly attenuated LPS-induced ALI in mice via the reduction of inflammatory cytokine production, protein concentration in BALF, pathological changes, and macrophage infiltration. Moreover, 8 f displayed a potential inhibitory effect on MAPKs/NF- $\kappa B$ activation of LPS-stimulated MPMs. These multifunctional properties highlight $\mathbf{8 f}$ as a promising candidate for further studies aimed at the development of novel anti-inflammatory drugs to treat ALI.

\section{Acknowledgments}

Financial support was provided by the National Natural Science Funding of China (81773579, 21472142, 21572166) and Zhejiang Natural Science Funding (LY17B020008).

\section{Disclosure}

The authors report no conflicts of interest in this work.

\section{References}

1. Matthay MA, Zemans RL. The acute respiratory distress syndrome: pathogenesis and treatment. Annu Rev Pathol. 2011;6:147-163.

2. Grailer JJ, Canning BA, Kalbitz M, et al. Critical role for the NLRP3 inflammasome during acute lung injury. J Immunol. 2014;192(12): 5974-5983.

3. Zhu Q, He G, Wang J, Wang Y, Chen W, Guo T. Down-regulation of toll-like receptor 4 alleviates intestinal ischemia reperfusion injury and acute lung injury in mice. Oncotarget. 2017;8(8):13678-13689.

4. Deng JC, Standiford TJ. Growth factors and cytokines in acute lung injury. Compr Physiol. 2011;1:81-104. 
5. Imam F, Al-Harbi NO, Al-Harbi MM, et al. Diosmin downregulates the expression of $\mathrm{T}$ cell receptors, pro-inflammatory cytokines and NF- $\mathrm{KB}$ activation against LPS-induced acute lung injury in mice. Pharmacol Res. 2015;102(1):1-11.

6. Qi T, Xu F, Yan X, Li S, Li H. Sulforaphane exerts anti-inflammatory effects against lipopolysaccharide-induced acute lung injury in mice through the Nrf2/ARE pathway. Int J Mol Med. 2016;37(1):182-188.

7. Merrill JC, You J, Constable C, Leeman SE, Amar S. Whole-body deletion of LPS-induced TNF- $\alpha$ factor (LITAF) markedly improves experimental endotoxic shock and inflammatory arthritis. Proc Natl Acad Sci U S A. 2011;108(52):21247-21252.

8. Lee IS, Lim J, Gal J, et al. Anti-inflammatory activity of xanthohumol involves heme oxygenase-1 induction via NRF2-ARE signaling in microglial BV2 cells. Neurochem Int. 2011;58(2):153-160.

9. Viola K, Kopf S, Rarova L, et al. Xanthohumol attenuates tumour cell-mediated breaching of the lymphendothelial barrier and prevents intravasation and metastasis. Arch Toxicol. 2013;87(7):1301-1312.

10. Yong WK, Ho YF, Malek SN. Xanthohumol induces apoptosis and $\mathrm{S}$ phase cell cycle arrest in A549 non-small cell lung cancer cells. Pharmacogn Mag. 2015;11(Suppl 2):275-283.

11. Hartkorn A, Hoffmann F, Ajamieh H, et al. Antioxidant effects of xanthohumol and functional impact on hepatic ischemia-reperfusion injury. J Nat Prod. 2009;72(10):1741-1747.

12. Costa R, Rodrigues I, Guardão L, et al. Modulation of VEGF signaling in a mouse model of diabetes by xanthohumol and 8-prenylnaringenin: Unveiling the angiogenic paradox and metabolism interplay. Mol Nutr Food Res. 2017;61(4).

13. Costa R, Negrão R, Valente I, et al. Xanthohumol modulates inflammation, oxidative stress, and angiogenesis in type 1 diabetic rat skin wound healing. J Nat Prod. 2013;76(11):2047-2053.

14. Cho YC, You SK, Kim HJ, Cho CW, Lee IS, Kang BY. Xanthohumol inhibits IL-12 production and reduces chronic allergic contact dermatitis. Int Immunopharmacol. 2010;10(5):556-561.

15. Avula B, Ganzera M, Warnick JE, Feltenstein MW, Sufka KJ, Khan IA. High-performance liquid chromatographic determination of xanthohumol in rat plasma, urine, and fecal samples. J Chromatogr Sci. 2004;42(7):378-382.

16. Butkevich AN, Ranieri B, Meerpoel L, et al. Synthesis of substituted indenones and indanones by a Suzuki-Miyaura coupling/acid-promoted cyclisation sequence. Org Biomol Chem. 2014;12(5):728-731.

17. Tang ML, Zhong C, Liu ZY, Peng P, Liu XH, Sun X. Discovery of novel sesquistilbene indanone analogues as potent anti-inflammatory agents. Eur J Med Chem. 2016;113(5):63-74.

18. Shrestha A, Jin Oh H, Kim MJ, et al. Design, synthesis, and structureactivity relationship study of halogen containing 2-benzylidene1-indanone derivatives for inhibition of LPS-stimulated ROS production in RAW 264.7 macrophages. Eur J Med Chem. 2017;133(6): $121-138$.
19. Singh A, Fatima K, Singh A, et al. Anticancer activity and toxicity profiles of 2-benzylidene indanone lead molecule. Eur J Pharm Sci. 2015;76(8):57-67.

20. Shintani EY, Uchida KM. Donepezil: an anticholinesterase inhibitor for Alzheimer's disease. Am J Health Syst Pharm. 1997;54(24): 2805-2810.

21. Zhu H, Xu T, Qiu C, et al. Synthesis and optimization of novel allylated mono-carbonyl analogs of curcumin (MACs) act as potent antiinflammatory agents against LPS-induced acute lung injury (ALI) in rats. Eur J Med Chem. 2016;121:181-193.

22. Liu Z, Tang L, Zou P, et al. Synthesis and biological evaluation of allylated and prenylated mono-carbonyl analogs of curcumin as antiinflammatory agents. Eur J Med Chem. 2014;74(3):671-682.

23. Bueltmann M, Kong X, Mertens M, et al. Inhaled milrinone attenuates experimental acute lung injury. Intensive Care Med. 2009;35(1) $171-178$.

24. Tsai YF, Yu HP, Chang WY, Liu FC, Huang ZC, Hwang TL. Sirtinol inhibits neutrophil elastase activity and attenuates lipopolysaccharidemediated acute lung injury in mice. Sci Rep. 2015;5:8347-8356.

25. Mogensen TH. Pathogen recognition and inflammatory signaling in innate immune defenses. Clin Microbiol Rev. 2009;22(2):240-273.

26. Franz KM, Kagan JC. Innate immune receptors as competitive determinants of cell fate. Mol Cell. 2017;66(6):750-760.

27. Bednash JS, Weathington N, Londino J, et al. Targeting the deubiquitinase STAMBP inhibits NALP7 inflammasome activity. Nat Commun. 2017;8:15203-15216.

28. Zhou Y, Liu T, Duan JX, et al. Soluble epoxide hydrolase inhibitor attenuates lipopolysaccharide-induced acute lung injury and improves survival in mice. Shock. 2017;47(5):638-645

29. Liu Z, Tang L, Zhu H, et al. Design, synthesis, and structure-activity relationship study of novel indole-2-carboxamide derivatives as antiinflammatory agents for the treatment of sepsis. J Med Chem. 2016; 59(10):4637-4650.

30. Joh EH, Gu W, Kim DH. Echinocystic acid ameliorates lung inflammation in mice and alveolar macrophages by inhibiting the binding of LPS to TLR4 in NF-אB and MAPK pathways. Biochem Pharmacol. 2012;84(3):331-340.

31. Jeong DH, Kim KB, Kim MJ, Kang BK, Ahn DH. Skipjack tuna (Katsuwonus pelamis) eyeball oil exerts an anti-inflammatory effect by inhibiting NF- $\kappa \mathrm{B}$ and MAPK activation in LPS-induced RAW 264.7 cells and croton oil-treated mice. Int Immunopharmacol. 2016;40(11) 50-56

\section{Publish your work in this journal}

Drug Design, Development and Therapy is an international, peerreviewed open-access journal that spans the spectrum of drug design and development through to clinical applications. Clinical outcomes, patient safety, and programs for the development and effective, safe, and sustained use of medicines are the features of the journal, which

\section{Dovepress}

has also been accepted for indexing on PubMed Central. The manuscript management system is completely online and includes a very quick and fair peer-review system, which is all easy to use. Visit http://www.dovepress.com/testimonials.php to read real quotes from published authors. 